\title{
"Desde menor, a minha escola é minha favela": Uma análise sobre o funk enquanto recurso pedagógico de educação nas aulas de História e Sociologia
}

"Since I was a Child, my School is my Favela": An Analysis of Funk as a Pedagogical Device of Education in History Classes and Sociology

Juliana da Silva Bragança*

Ingra Daniela dos Santos Maciel ${ }^{\star *}$

RESUMO

O debate sobre a criminalização do funk vem se intensificando nos últimos anos. Em 2019, a prisão do DJ Rennan da Penha sob provas questionáveis fomentou ainda mais os debates que giram em torno deste tema. Alguns meses depois, o massacre por parte da Polícia Militar do Estado de São Paulo contra adolescentes e jovens presentes no Baile da DZ-7, em Paraisópolis (cidade de São Paulo), deixou um saldo de 9 mortos e a certeza de que o debate sobre a criminalização do funk e a perseguição contra suas manifestações (sobretudo bailes funk) e seus adeptos estão longe de ser esgotados. Este artigo apresenta sugestões de como inserir estes debates na sala de aula com vistas a romper com a histórica criminalização do funk.

Palavras-chaves: funk carioca; História; ensino.

\section{ABSTRACT}

The debate on the criminalization of funk has intensified in recent years. About 1 year ago, the arrest of DJ Rennan da Penha under questionable evidence has further fueled the debates surrounding this topic. A few months later, the massacre by the Military Police of the State of São Paulo against teenagers and young people present at the Baile da DZ-7, in Paraisópolis (favela in the South Zone of the city of São Paulo) left a balance of 9 dead and the certainty that the debate on the criminalization of funk and the persecution of its manifestations (especially funk dances) and its supporters is far from exhausted. This article presents suggestions on how to insert these debates in the classroom with a view to breaking with the historic criminalization of funk based on experiences with the application of funk in Rio as a teaching object.

Keywords: funk from Rio; History; teaching.

\footnotetext{
* Universidade Federal Rural do Rio de Janeiro (UFRRJ), Seropédica, RJ, Brasil. jsilvabraganca@ gmail.com

** Universidade Federal do Estado do Rio de Janeiro (UNIRIO), Rio de Janeiro, RJ, Brasil. ingradaniela@gmail.com
} 
Há algum tempo vêm sendo levantados intensos e produtivos debates acerca da utilização da música como objeto de pesquisa e meio de ensino-aprendizagem em sala de aula. Sobre o assunto, destaca-se a figura do historiador Marcos Napolitano, por defender e apontar caminhos acerca destas possíveis abordagens. Segundo ele, em entrevista publicada na Revista História Hoje, um dos maiores desafios dos historiadores/professores de História é justamente a questão metodológica. Comumente nos encontramos diante de difíceis questões e, desta forma, indagam Soares e Hermeto (2017, p. 143): "como incorporar a escuta musical na análise da canção?"; "como levar a música para a sala de aula com uma proposta séria e qualificada?"; "de que forma posso atrelar o gosto musical dos estudantes em minhas aulas?"; "como apresentar novas canções/ritmos ao meu alunado?” Além do mais, tal como preconizou Paulo Freire em Pedagogia da Autonomia, é importante que os educandos tenham seus saberes respeitados por parte dos educadores. Esse respeito perpassa tanto por não ignorar e/ou diminuir estes saberes quanto por inseri-los no cotidiano do processo de ensino-aprendizagem.

Nesse sentido, o objetivo principal deste artigo está centrado em demonstrar, por meio das experiências exitosas de uma das autoras enquanto professora de História e Sociologia no ensino médio da rede pública estadual, que é sim possível trabalhar com uma escuta atenta de músicas na sala de aula, especificamente de músicas funk. A título de exemplo, serão demonstradas duas experiências: uma em História, com a canção "Não Foi Cabral”, da MC Carol, e outra em Sociologia, com a canção "Liberdade dos Funkeiros", dos MCs Márcio e Goró.

\section{MÚSICA NA SALA DE AULA}

Analisar as formas e os movimentos que são construídos a partir da emissão sonora de cantos e instrumentos como meios de compreender as diversas manifestações sociais, culturais, religiosas e políticas sobre a relação de homens e mulheres com a música e as formas de sociabilidade de que ela dispõe em relação ao passado e ao presente. Ou seja, trata-se do uso da música enquanto fonte histórica e sociológica para compreensão das sociedades - sejam elas nativas, tradicionais, quilombolas, ou qualquer outra que tenha a musicalidade na construção de sua memória. 
O comportamento humano observado a partir da ótica histórica, sociológica ou até mesmo antropológica, em relação ao campo musical, traz ferramentas sobre símbolos de sociabilidade do indivíduo, expressões, corporeidade e identidade. E pode, assim, fornecer material de estudo para ser trabalhado em sala de aula. A partir de 1970, a História - enquanto campo de construção social e científica - vem debruçando-se sobre a música enquanto fonte e material de estudo na formação escolar, através da oralidade e/ou da escrita. Desta forma, nota-se que o papel do educador-historiador deve ser utilizar a fonte histórica como um elemento pedagógico que possibilite o processo de ensino-aprendizagem. Assim, segundo Bosi, a linguagem é o instrumento socializador da memória, tendo em vista que ela reduz, unifica e aproxima, no mesmo espaço histórico e cultural, vivências tão diversas como o sonho, as lembranças e as experiências recentes (BOSI, p. 18, 1979).

É importante, segundo Napolitano, que haja "uma combinação entre o gosto musical dos estudantes e a ampliação de seu repertório, como eixo de planejamento das atividades" (2017, p. 144). A escola não deve estar presa ao gosto musical de seu público, bem como não deve desprezá-lo nem impor um repertório que não considere suas experiências, preferências e sua bagagem cultural, tendo o corpo docente o dever de se desprender de conceitos pré-concebidos. No entanto, é importante que a escola esteja também comprometida em ir além, em ultrapassar os limites das barreiras colocadas pelos estudantes. Ou seja, há paralelos entre a preservação da memória e identidade desses públicos que vivenciam essa cultura tanto na escrita de Bosi (1979) quanto na de Napolitano (2017).

Para Napolitano, é interessante que a música não seja encarada como mera diversão e que, ao contrário disso, a canção seja vista como um documento histórico a ser analisado por aqueles que hão de escutá-la. Assim, a escuta de uma canção é a análise de um documento histórico e faz parte da aula ministrada; por isso, deve estar interligada com o assunto a ser estudado e debatido, instruindo os educandos a construírem um discernimento sobre o documento, permitindo que eles sejam capazes de diferenciar na leitura temporalidade e espacialidade (SOARES e HERMETO, 2017, p. 144-145). Nesse sentido, a música é aqui vista e defendida como objeto de estudo e como fonte que pode vir a contribuir com as aprendizagens e a construção de conhecimentos históricos pelos educandos, desde que:

a) os estudantes sejam convidados a refletir sobre o contexto histórico de 
sua produção e/ou sobre o conteúdo com o qual a canção está vinculada;

b) o repertório dos alunos seja levado em conta;

c) haja uma audição atenta da canção e

d) o professor tenha como ponto de partida um roteiro de abordagem assim, o processo de ensino-aprendizagem pode se tornar mais interativo, proveitoso e eficiente.

Ressalta-se ainda que a inserção da musicalidade e do trabalho feito pela disciplina de música em sala de aula deve ocorrer tendo em vista que, em agosto de 2008, o Governo Federal sancionou a lei 11.769 (que altera a Lei de Diretrizes e Bases da Educação - lei n. 9.394 de dezembro de 1996) no âmbito do ensino de música para o ensino fundamental (CERTOLLIN, 2015). Esta prerrogativa traz para o campo da educação mais opções para serem trabalhadas e socializadas com os alunos da educação básica. Ou seja, a musicalidade não deve ser pensada apenas como um instrumento obrigatório, mas também como ferramenta e fonte para o ensino de História e Sociologia.

\section{O FUNK}

Para início de conversa, precisamos salientar que a música já vem sendo amplamente utilizada na sala de aula em propostas consistentes por parte de vários professores em diversos componentes curriculares. É bem provável que isto esteja intimamente relacionado ao fato de a música ter ganhado espaço na academia como objeto de pesquisa. Na grande área da História, é notável que esta abertura seja intrínseca à grande mudança de paradigmas promovida por Marc Bloch e Lucien Febvre através da Escola dos Annales e que reverbera ainda hoje na produção historiográfica. Ambos os historiadores defenderam a utilização de novas fontes de pesquisa para a compreensão do passado. Assim, apesar de certa resistência no início, a música começou a ser encarada como uma importante fonte de estudo em História. Cabe aqui destacar a contribuição de Eric Hobsbawn, com a obra História Social do Jazz. Quando lançou o livro pela primeira vez, no ano de 1959, o historiador usou o pseudônimo Francis Newton para separar o seu trabalho de jornalista do de historiador, segundo Menezes (2014).

Hoje, porém, a música já é reconhecida como uma importante fonte de 
estudo em História. Esse movimento pode ser verificado, sobretudo, através do direcionamento das pesquisas em História entre dois períodos específicos da História brasileira: os anos 1930 e os anos 1960-1980 (atrelados, respectivamente, à Era Vargas e ao período da Ditadura Civil-Militar). Há, portanto, a necessidade de nós, historiadoras e historiadores, rompermos com esse limite e abraçarmos outros ritmos e gêneros musicais tanto como objeto de pesquisa quanto na utilização em sala de aula. E é aqui que o funk é inserido. Tal como MC Bob Rum deixou registrado no clássico "Rap da Felicidade": "O funk não é modismo / É uma necessidade".

Neste aspecto, para entender o gênero musical funk que hoje é conhecido e difundido na cultura carioca e outras, é preciso reconectar-se com os guetos caribenhos (VIANNA, 1997, p. 20) e entender as relações afro-diaspóricas constituídas a partir do processo de hibridização nas diásporas negra, como nos diz Gilroy acerca da construção da música no mundo atlântico negro. Segundo ele,

Examinar o lugar da música no mundo atlântico negro significa observar a autocompreensão articulada pelos músicos que a têm produzido, o uso simbólico que lhe é dado por outros artistas e escritores negros e as relações sociais que têm produzido e reproduzido a cultura expressiva única, na qual a música constitui um elemento central e mesmo fundamental. (GILROY, 2001, p.161)

Em outras palavras, Gilroy pontua que falar sobre o uso da música negra é fundamental para o processo de encorajamento das populações diaspóricas. Desta forma, o intuito do ensino da História do funk, mesmo tratando-se de um gênero híbrido, é significativo para apontar mecanismos sobre a História e cultura afro-brasileira (corroborando assim com o cumprimento da lei 11.645/08), ${ }^{1}$ buscando a emancipação da juventude por meio da música e de suas narrativas. Isso porque o movimento funk representa um dos maiores fenômenos de massa do Brasil, sendo este concebido pela juventude negra e pobre do Rio de Janeiro como uma importante fonte de lazer (HERSCHMANN, 2005, p. 28).

De meados da década de 1990 para cá, o funk vem atraindo também a classe média, sendo então assimilado como um produto da indústria cultural. Nesse sentido, e também tendo em vista o grande sucesso alcançado por alguns artistas na atualidade (tais como Anitta, Ludmilla e MC Kevin o Chris, por exemplo) é justo afirmar que o funk continua fazendo parte da cena cultural 
juvenil de forma notória, destacando-se, inclusive, como uma possibilidade de ascensão social desses sujeitos.

No entanto, apesar de todo o sucesso conquistado em âmbito nacional e internacional, o movimento funk continua sendo alvo de perseguições, reflexo dos preconceitos e das discriminações contra o estilo de vida e da origem racial e social da maioria dos funkeiros. A música funk está fincada em tradições musicais populares negras tanto brasileiras quanto estadunidenses ${ }^{2}$ e contam, de forma geral, com uma linguagem coloquial [...] acompanhada de efeitos sonoros eletrônicos, sem que seja estritamente necessário contar com educação musical formal para garantir espaço no mundo funk. (BRAGANÇA, 2020, p. 29)

O movimento funk nacional completou em 2019 trinta anos de existência e, ao longo destes anos, vem passando por diversas transformações. O surgimento do funk carioca como um movimento cultural local está associado ao lançamento da série de discos Funk Brasil pelo DJ Marlboro. O primeiro deles, Funk Brasil I, foi lançado pela Polygram em 1989, bateu a marca de 250 mil cópias vendidas e consagrou o início da era das melôs ${ }^{3}$ (BRAGANÇA, 2020, p. 34).

Figura 1 - Capa do disco Funk Brasil, lançado pelo DJ Marlboro em 1989. É considerado por alguns autores como o marco da "nacionalização" do funk.

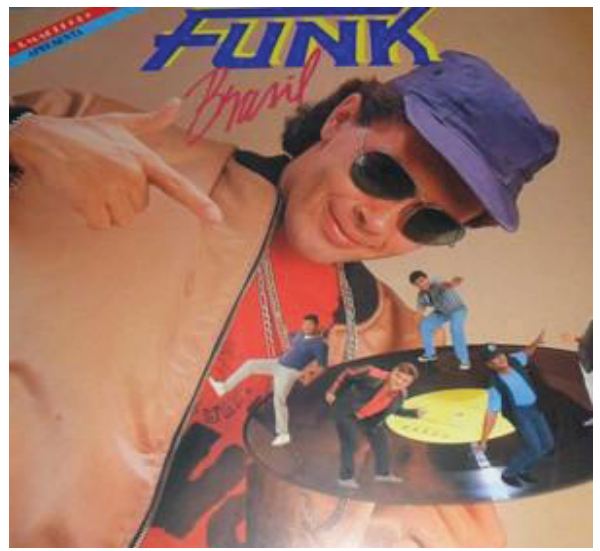

Fonte: ons://g1.globo.com/rio-de-janeiro/ noticia/2012/08/musical-conta-historia-de-4decadas-do-funk-no-brasil-relembre-40-hits. html. Acesso em 24 jul. 2020. 
Posteriormente, já na década de 1990, emergiu na cena funk a vertente nomeada de funk melody. Nela, permaneceram os ritmos inspirados no miami bass; porém, enquanto as melôs contavam com grande irreverência em suas letras zombeteiras, o funk melody apresentava poesias essencialmente românticas. Dois MCs que ganharam notoriedade na cena funk com esta vertente, foram Claudinho e Buchecha. Muitas de suas canções alcançaram grande sucesso e seus discos tiveram vendas muitas vezes impressionantes (BRAGANÇA, 2019, p. 38-39).

Figura 2 - Capa do disco Claudinho e Buchecha, primeiro disco da dupla, lançado em 1996.

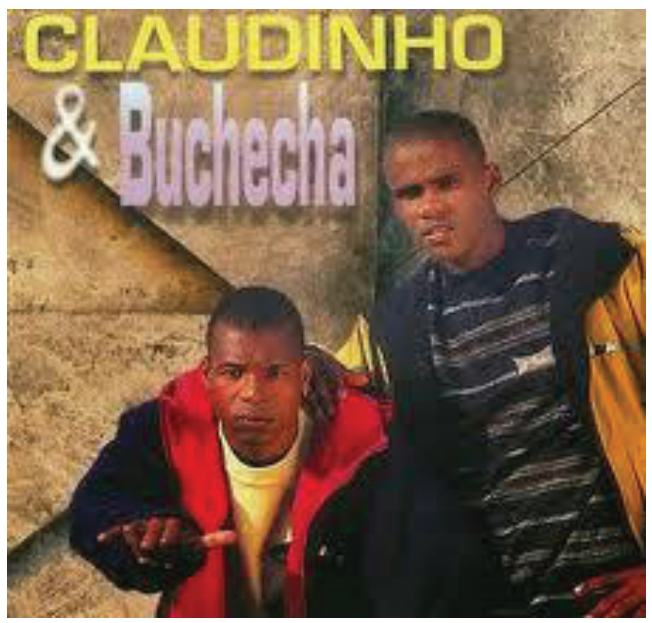

Fonte: https://upload.wikimedia.org/wikipedia/ pt/e/ef/Claudinho_\%26_Buchecha_\%C3\% A1lbum.jpg. Acesso em: 24 jul. 2020.

Concomitantemente ao funk melody, surgia também o funk consciente, que trazia à tona a realidade das favelas, abordando temas que giravam em torno das carências que a população favelada era (e ainda é) obrigada a enfrentar. "Nelas, eram utilizadas melodias diversas, com ritmos/batidas descontraídos ou que soassem bastante 'violentos', devido à presença de timbres muito graves” (BRAGANÇA, 2020, p. 39). Apesar de não terem sido consideradas músicas que promoviam apologia ao crime e/ou ao criminoso, as músicas que 
se enquadravam nesta vertente eram estigmatizadas, como nos disse Antônio Aragoso - dono de equipe de som Espião - em entrevista realizada em 2017. ${ }^{4}$

Os MCs Cidinho \& Doca, dupla oriunda da Cidade de Deus, são, sem dúvida, os maiores representantes do funk consciente.

Figura 3 - MC Doca e MC Cidinho, representantes da "velha guarda" do funk. A dupla lançou músicas que alcançaram muito sucesso, como a clássica "Rap da Felicidade". Em outubro de 2019, a dupla se apresentou no Espaço Favela, no Rock in Rio, demonstrando o destaque e o reconhecimento da dupla na cena funk e no cenário musical como um todo.

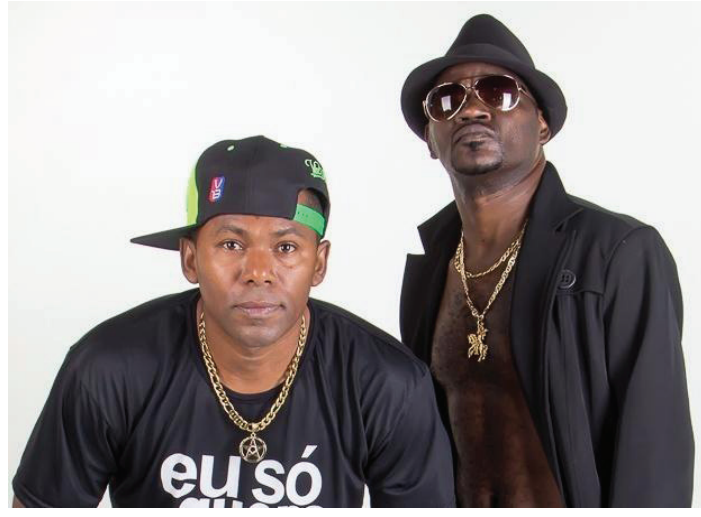

Fonte: ons://www.epopnaweb.com.br/funk-de-cidinho-edoca-rap-da-felicidade-completa-21-anos/. Acesso em: 24 jul. 2020.

O funk proibidão, no que lhe concerne, alcançou grande sucesso a partir dos anos 2000. São músicas do funk proibidão aquelas que "contam, de forma realista e por vezes até entusiástica [...] histórias em que os traficantes impuseram seu poder contra os oponentes (a polícia ou as facções criminosas rivais) e fizeram valer sua lei" (ESSINGER, 2005, p. 227). Grandes nomes da cena funk tiveram sérios problemas com a polícia: alguns foram intimados para depor em delegacias, por vezes acusados de envolvimento com o tráfico de drogas (FACINA, 2013, p. 30); outros chegaram a ser presos. 
Figura 4 - prisão de MCs acusados de promoverem apologia ao crime e ao criminoso em 2010. Da esquerda para a direita: MC Tikão, MC Smith, MC Frank e MC Max.

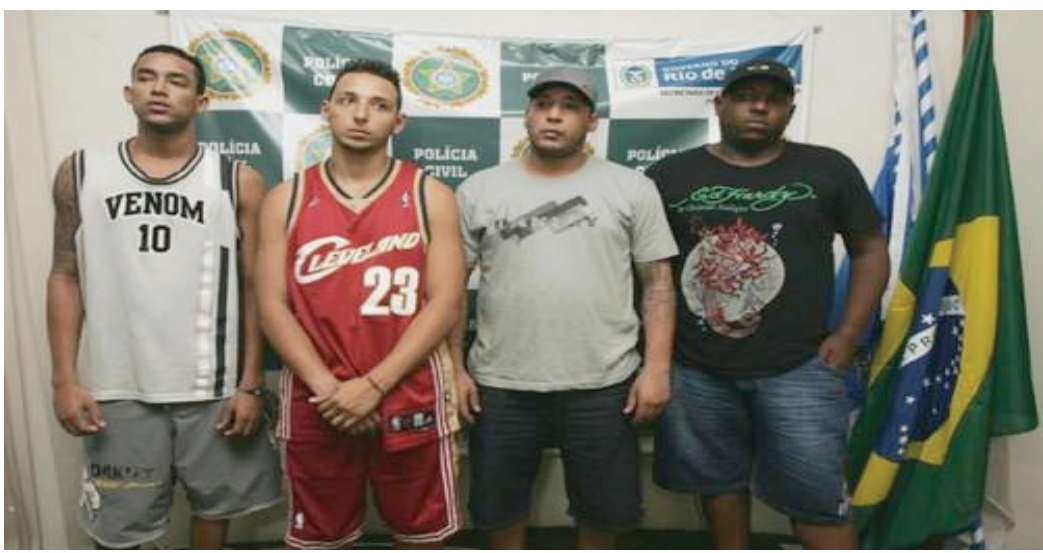

Fonte: http://apafunk.blogspot.com/2010/12/justica-revoga-prisoes-de-mcs.html. Acesso em 24 jul. 2020.

O funk proibidão emergiu na cena no início dos anos 2000 e "está mais associado à realidade das favelas no que concerne ao comércio varejista de drogas e à vida daqueles que com ele estão envolvidos, hora em tom glorioso, hora em tom pessimista" (BRAGANÇA, 2020, p. 40).

“A Firma é Forte", canção interpretada por MC Tikão e MC Frank, é um dos grandes hinos do funk proibidão:

A firma é forte / Os verme desacreditou / Que a mira é a laser / Entrou em pânico / Nosso bonde é chapa quente / Bala vai cantar / É a equipe O Predador / Eu o na $\mathrm{VK}^{5}$ / [...] / Nosso bonde é chapa quente / É melhor tu se ligar / [...] Canta aí que eu to ligado / Só bandido e traficante / [...] / Aqui o bagulho é doido / E eu to cheio de bola / Tem fuzil AR156 / E também várias pistola / [...] / E bala no caveirão / Se tentar entrar na VK / Vai tomar só rajadão ${ }^{7}$

Ainda no contexto que envolve os funks do tipo proibidão, é importante uma reflexão sobre a música de Tikão e Frank para o processo de construção e análise social que podem ser feitas através do debate com jovens de ensino médio, atrelando as percepções desses grupos ao contexto histórico e social no qual os MCs produzem suas letras. Por outro lado, deve ser papel da academia um 
olhar mais apurado sobre essas letras de forma a não marginalizar ou reproduzir estereótipos racistas por um instrumento já tão estigmatizado, contribuindo de forma eficaz para uma compreensão histórica e social da cultura funk.

O início dos anos 2000 foi também um grande marco para as mulheres na cena funk carioca: foi quando teve início a participação ativa de mulheres artistas, que antes tinham um espaço muito pequeno, estando elas limitadas, nos palcos, ao papel de dançarinas. Este foi um importante marco na história do movimento funk, tendo em vista que a emergência das mulheres enquanto protagonistas das suas vivências e realidade sexual, esse momento e inserção dessas cantoras, alterou profunda e decisivamente o movimento. Foi a partir de então que o funk alcançou um patamar midiático como ainda não havia sido visto antes e que, hoje sabemos, continuou em ascensão.

O funk putaria se destaca principalmente pelo fato de ter sido o meio principal em que as mulheres conseguiram conquistar espaço e se colocar entre suas maiores representantes. O grande marco desta vertente foi o lançamento da MC Tati Quebra-Barraco no mundo funk, inaugurando uma nova fase do movimento, ao mesmo tempo em que se consagrava como a primeira grande expoente do funk erótico, ${ }^{8}$ abrindo espaço para as demais artistas que passaram a tratar abertamente da sua própria sexualidade em diversas canções. Com letras irreverentes e corajosas, Tati Quebra-Barraco lançou seu primeiro disco em 2001 pela equipe Pipo's. Dentre seus grandes sucessos, podemos destacar Montagem Ardendo Assopra, que versava sobre algumas posições sexuais: "Sessenta e nove, frango assado / De ladinho a gente gosta / Se tu não tá aguentando, para um pouquinho, tá ardendo assopra". $\mathrm{A}$ MC também desafiou os padrões de beleza e do lugar ocupado pela mulher no que diz respeito a relações sexuais, quando afirmou "Sou feia mas tô na moda / Tô podendo pagar hotel pros homem / Isso que é mais importante". ${ }^{10}$ (BRAGANÇA, 2020, p. 43)

Ainda nesse contexto, a autora Lopes nos traz uma reflexão acerca de questionamentos sobre a sexualidade das mulheres no mundo funk, esse apontamento pode ser pensado a partir das letras do funk putaria, narrado por funkeiras. Sobre isso, Lopes diz: que a erotização do funk não deve ser vista como um fenômeno singular e isolado, uma vez que "sexo" não é um tema estranho às manifestações da diáspora africana constitutivas da cultura brasileira (LOPES, 2011, p. 158). 
Figura 5 - Com letras polêmicas, irreverentes e eróticas, Tati Quebra-Barraco foi uma das primeiras artistas femininas a conquistar espaço na cena funk. A MC faz parte de um processo de modificação profunda do movimento.

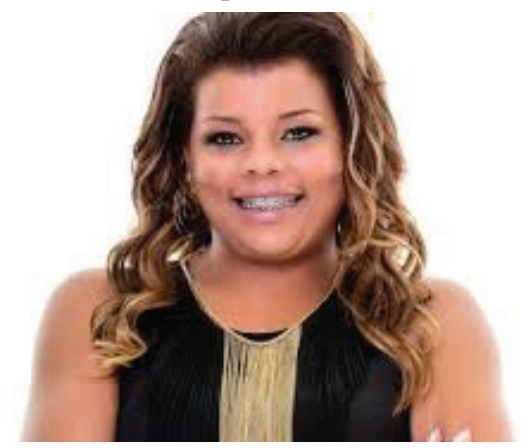

Fonte: https://heloisatolipan.com.br/musica/exclu sivo-tati-quebra-barraco-fala-sobre-novo-realityshow-na-fox-brasil-album-mulheres-no-funk-asnovas-vertentes-do-genero-e-vida-no-morro/. Acesso em: 24 jul. 2020.

\section{Assim,}

Com uma linguagem moderna e de fácil apelo entre jovens, principalmente nas periferias, o funk deixa de ser percebido pelo seu aspecto meramente musical e passa a ser considerado uma linguagem de "negros e favelados", descendente em parte de batuques africanos e espaço por excelência da agência negra. (SOUZA; SILVA, 2017, p. 194)

A partir desta breve apresentação da história do funk, não restam dúvidas de que o movimento apresenta uma diversidade incrível de temas que podem (e devem!) ser abordados e debatidos no próprio movimento funk, na academia e também, é claro, na sala de aula.

A lei federal 10.639, de 2003, foi uma importante conquista do movimento negro no Brasil: ela tornou obrigatório o ensino da história e da cultura afro-bra- 
sileira nas escolas brasileiras. Por outro lado, compreender a sua não utilização em espaços de educação é fundamental. A utilização do funk em sala de aula faz parte do processo de validação da cultura afro-brasileira. Posteriormente, em 2008, ela foi alterada e entrou em vigor a lei 11.645, que inclui também a história e a cultura indígena. Portanto, sendo o funk uma das várias expressões da cultura negra em nosso país, sua utilização em sala de aula é respaldada por lei.

Além disso, o movimento funk vem, ao longo de sua história, sofrendo vários ataques e sendo constantemente vítima de um longo processo de criminalização. Exemplo atual da criminalização dos funkeiros foi a prisão do DJ Rennan da Penha no início de 2019. Ele é o principal expoente do funk 150 BPM (batidas por minuto) - um funk com ritmo muito mais acelerado, recheado de putaria - e o principal responsável por realocar a cena funk de São Paulo para o Rio de Janeiro. Os bailes que o DJ promovia na Penha - Zona Norte do Rio atraíam mais de 25 mil pessoas, inclusive artistas. Seu sucesso também pode ser notado pelo fato de um dos clipes em que esteve envolvido na produção foi indicado a concorrer ao Grammy Latino. ${ }^{11}$ A carreira do DJ Rennan da Penha, no

Figura 6 - O DJ Rennan da Penha foi preso em 2019 sob acusação de associação ao tráfico de drogas. Sua prisão é um exemplo atual da histórica perseguição contra os funkeiros.

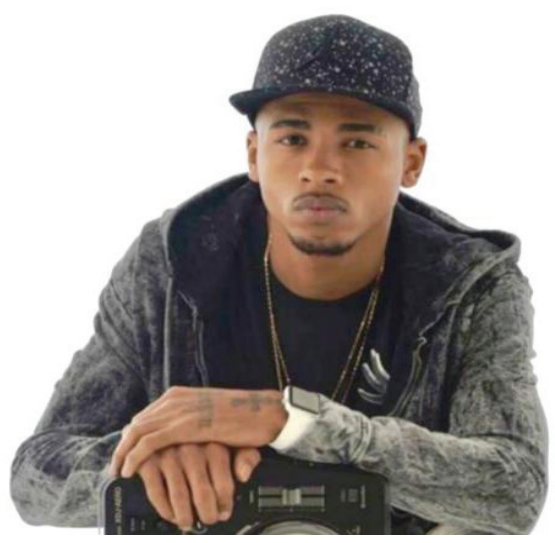

Fonte: https://odia.ig.com.br/rio-de-janeiro/2019/ 03/5629950-confira-os-motivos-que-levaram-desembargadores-a-determinar-prisao-de-rennan-da-penha.html. Acesso em 24 jul. 2020. 
entanto, sofreu uma interrupção pela sua prisão, sob provas questionáveis, por associação ao tráfico de drogas. ${ }^{12}$ Esse histórico de criminalização da cultura negra brasileira precisa, portanto, ser incansavelmente debatido em sala de aula, tendo em vista que é um processo que ainda está em curso.

É neste contexto que pensar a música funk e suas ligações afro-diaspóricas é uma das maneiras de compreender como as relações étnico-raciais historicamente foram sendo desenvolvidas e como estes elementos contribuem para pensar o ensino de História e Sociologia para as juventudes pobres e periféricas.

Além disso, conforme já demonstrado, o funk faz parte do cotidiano, do lazer e das experiências de grande parte da juventude brasileira e, consequentemente, dos estudantes tanto do ensino médio quanto do ensino fundamental. Vale mencionar ainda que aproximar a juventude de aspectos culturais que envolvam a formação de suas identidades é um processo fundamental para a construção de outras narrativas históricas que proporcionem o reconhecimento dessa identidade e façam aflorar, de forma consciente, o sentimento de pertença.

No tocante ao que diz respeito à “juventude", é importante também destacar que, por um longo período, o conceito de juventude não era atribuído àqueles que viviam nos espaços pobres e periféricos da cidade. $\mathrm{O}$ conceito de juventude era um termo atribuído apenas àqueles que viviam em espaços e condições de privilégio social (CARVALHO, 2007, p. 23).

A utilização do funk em sala de aula também deve ser defendida tendo em vista que ela pode aproximar os conteúdos da escola à realidade dos estudantes, uma vez que, tal como defendido por Paulo Freire, ensinar exige respeito ao saberes dos educandos (FREIRE, 1996, p. 15). Assim, o uso do gênero musical funk em sala de aula deve fazer parte da aproximação dos saberes apresentado pelos alunos, colaborando também para a construção de uma educação antirracista.

Tendo como ponto de partida as informações aqui apresentadas, serão descritas duas experiências exitosas da utilização do funk carioca em sala de aula, no processo de ensino-aprendizagem. Ambas foram realizadas com alunos da rede pública da Bahia, no Colégio Estadual do Campo de Ibititá (CECI), onde uma das autoras é efetiva e atua como professora de História, Sociologia e Filosofia nas três séries do Ensino Médio.

Ibititá é uma pequena cidade do interior da Bahia e, ao contrário do que 
se pode pressupor, recebe grande influência do funk. Isto pode ser comprovado pelo seguinte fato: em 2019, alguns alunos do $3^{\circ}$ ano se uniram e promoveram duas edições da festa Elletrofunk. O evento, em suas duas edições, reuniu cerca de 400 pessoas em cada festa e contou com a participação de grandes nomes da cena funk atual, tais como DJ Tia Carol, famosa pelo seu envolvimento com a festa Batekoo. ${ }^{13}$ A escolha pela utilização do funk carioca nas salas de aula do CECI se deu por dois motivos principais: 1) a aproximação da professora com o funk carioca, tema sobre o qual pesquisa e no qual é especialista e 2) o contato dos alunos com o funk e sua apreciação.

As atividades realizadas foram pensadas tendo em vista a Base Nacional Comum Curricular (BNCC) $)^{14}$ e tiveram como base a competência de número cinco $^{15}$ das Ciências Humanas Sociais e Aplicadas para o Ensino Médio: "Identificar e combater as diversas formas de injustiça, preconceito e violência, adotando princípios éticos, democráticos, inclusivos e solidários, e respeitando os Direitos Humanos" (BNCC, 2017, p. 570). ${ }^{16}$ Dentre as habilidades a serem desenvolvidas nos educandos a partir desta competência, são contempladas as de número dois e três, que podem ser conferidas a seguir:

2. Analisar situações da vida cotidiana, estilos de vida, valores, condutas etc., desnaturalizando e problematizando formas de desigualdade, preconceito, intolerância e discriminação, e identificar ações que promovam os Direitos Humanos, a solidariedade e o respeito às diferenças e às liberdades individuais [...] 3. Identificar diversas formas de violência (física, simbólica, psicológica etc.), suas principais vítimas, suas causas sociais, psicológicas e afetivas, seus significados e usos políticos, sociais e culturais, discutindo e avaliando mecanismos para combatê-las, com base em argumentos éticos. (BNCC, 2017, p. 577)

NÃO FOI CABRAL, MC CAROL

Entre os conteúdos previstos a serem aplicados no $2^{\circ}$ ano do Ensino Médio, está a chegada dos portugueses ao Brasil. Um dos grandes desafios dos professores de História é desenvolver esse conteúdo na sala de aula para além da visão dos colonizadores, mostrando como o processo colonial interferiu nas vidas dos indígenas que já habitavam esta terra. Com o objetivo de tornar o 
conteúdo mais atraente, a opção foi utilizar a música "Não foi Cabral”, de MC Carol, na turma $2^{\circ} \mathrm{A}$ do turno vespertino.

$\mathrm{Na}$ abertura da aula e do assunto a ser abordado no primeiro trimestre, foram lançadas as seguintes perguntas: "Quem aqui gosta de funk? Quem conhece a MC Carol?". As respostas foram bem variadas e o bate-papo fluiu de forma agradável e descontraída. Logo depois, foram levadas algumas informações básicas sobre a artista.

MC Carol, da cidade de Niterói (RJ), destaca-se hoje como uma das artistas mais notáveis do movimento funk. A artista possui canções que tratam de temas diversos: ela passeia sem dificuldades entre o funk putaria, o funk consciente e o funk proibidão. Algumas de suas músicas, tais como "Delação premiada", por exemplo, demonstram que os debates em torno da esfera política tradicional continuam fazendo parte do movimento e auxiliam na desconstrução da falsa ideia de que o funk é um gênero musical que produz canções "alienadas" e sem senso crítico. ${ }^{17}$

Em meados de 2015, a MC lançou a música "Não foi Cabral”, que questiona a construção da História "oficial” de nosso país, colocando em xeque o papel dos portugueses no início de nossa História. Iniciando com um remix do Hino Nacional e com tom agressivo, a canção é bem direta:

Professora me desculpe / Mas agora vou falar / Esse ano na escola / As coisas vão mudar / Nada contra ti / Não me leve a mal / Quem descobriu o Brasil / Não foi Cabral / Pedro Álvares Cabral / Chegou 22 de abril / Depois colonizou / Chamando de Pau-Brasil / Ninguém trouxe família / Muito menos filho / Porque já sabia / Que ia matar vários índios / Treze Caravelas / Trouxe muita morte / Um milhão de índio / Morreu de tuberculose / Falando de sofrimento / Dos tupis e guaranis / Lembrei do guerreiro / Quilombo Zumbi / Zumbi dos Palmares / Vitima de uma emboscada / Se não fosse a Dandara / Eu levava chicotada. (NÃO foi Cabral, MC Carol, 2015)

Assim, quando a MC questiona "a ideia de descobrimento numa chave eurocêntrica e passando a valorizar a experiência dos povos em contato na América portuguesa, Carol dialoga com perspectivas críticas na historiografia que têm revisitado temas canônicos" (SOUZA e SILVA, 2017, p. 192). 
Figura 7 - MC Carol, artista niteroiense, responsável pelo lançamento de canções funk atuais que contém temas políticos polêmicos, tais como a Operação Lava-Jato e o caloroso debate sobre o "descobrimento" do Brasil.

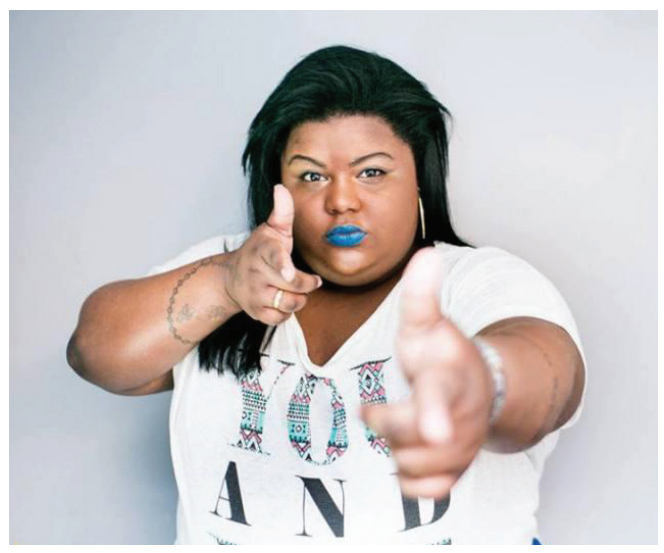

Fonte: http://www.diariodocentrodomundo.com.br/ delacao-premiada-mc-carol-e-nao-chico-oucaetano-faz-a-trilha-sonora-do-momento-politicodo-brasil-por-kiko-nogueira/mc-carol/. Acesso em: 24 jul. 2020.

Após a escuta da canção, com o acompanhamento da letra da música em seus celulares (foi permitido formar duplas para que todos tivessem acesso ao conteúdo da canção, enviado anteriormente via Whatsapp, e do livro didático - nem todos possuíam celular e não houve livros didáticos em número suficiente para todos os alunos da escola), pudemos começar a debater sobre a invasão do Brasil pelos portugueses e seu impacto para a população indígena.

"A colonização portuguesa na América" é o título do segundo capítulo do livro didático utilizado. A música serviu de complemento para as discussões em torno do pequeno subtítulo "Impactos da presença portuguesa para a população indígena" (BRAICK e MOTA, 2016, p. 37). ${ }^{18}$ O debate esteve centrado principalmente nas mortes dos indígenas com a chegada dos europeus, em suas diversas causas: doenças transmitidas pelos invasores, tais como a reincidência da tuberculose conforme citado em "Não foi Cabral", e os violentos conflitos entre indígenas e portugueses, que tinham maior poder bélico. Des- 
sa forma, foi possível também demonstrar o movimento de resistência indígena contra a invasão dos colonizadores, contrapondo assim a ideia de que os indígenas teriam aceitado pacificamente a colonização portuguesa. A canção utilizada serviu também como pontapé inicial para outros debates, tais como a violência sexual contra as mulheres indígenas e, no segundo trimestre, ela foi utilizada também para debater a resistência dos negros à escravidão no Brasil. ${ }^{19}$

Ao final da unidade, a música esteve presente na avaliação. ${ }^{20}$ Abaixo está transcrita a questão criada pela professora:

Pedro Álvares Cabral / Chegou 22 de abril / Depois colonizou / Chamando de Pau-Brasil / Ninguém trouxe família / Muito menos filho / Porque já sabia / Que ia matar vários índios / Treze Caravelas / Trouxe muita morte / Um milhão de índio / Morreu de tuberculose"

O trecho acima é da música "Não foi Cabral", da artista funkeira MC Carol. O trecho selecionado acima diz respeito:

a) À chegada dos portugueses no Brasil e à plantação de cana-de-açúcar através da plantation.

b) Aos rituais antropofágicos praticados entre muitos povos Tupi, tais como os Tamoio e os Tupinambá.

c) À chegada dos portugueses ao Brasil, que levou milhares de indígenas à morte em batalhas ou através da transmissão de doenças.

d) À importância da Igreja Católica no início da colonização portuguesa na América e a extração do pau-brasil.

e) Aos jesuítas que se preocuparam em aprender as línguas indígenas e ao projeto de missões que previa que cada família indígena morasse em uma residência.

A maior parte da turma acertou a questão, o que demonstra o sucesso da utilização desta música à aplicação do conteúdo sobre a chegada dos portugueses na América.

\section{LIBERDADE DOS FUNKEIROS, MCS MÁRCIO E GORÓ}

Entre os conteúdos abordados no segundo trimestre deste ano nas turmas de $2^{\circ}$ ano do turno matutino em Sociologia do CECI, estava "Democracia, cidadania e direitos humanos", título do sétimo capítulo do livro Sociologia em 
movimento (VÁRIOS, 2016, p. 170). As atividades descritas neste tópico foram aplicadas em três turmas. Seguindo as sugestões do livro, foram debatidos temas como a democracia e suas diferentes formas, ao longo da História e no Brasil atual; alguns teóricos da democracia moderna e contemporânea, tais como Rousseau, Montesquieu, Benjamin Constant e Rosa Luxemburgo, por exemplo; os conceitos de cidadania e direitos humanos. Os estudantes foram levados a refletir também, de forma geral, sobre os direitos políticos, civis e sociais que são garantidos constitucionalmente a todo cidadão brasileiro. $\mathrm{O}$ foco principal da abordagem deste capítulo, no entanto, foi a cidadania e os direitos humanos no Brasil.

Após o levantamento destes conceitos importantes ao longo de algumas aulas, partimos para a escuta atenta da canção "Liberdade dos Funkeiros", dos MCs Márcio e Goró (1995). Os alunos foram convidados a refletir sobre o contexto socioeconômico e político brasileiro dos anos 1990, época em que a canção foi produzida.

A música foi ouvida primeiramente sem interrupções. Os estudantes demonstraram grande interesse. Por ser uma música funk produzida no Rio de Janeiro na década de 1990, nenhum aluno das três turmas a conhecia, ou sequer havia ouvido falar dos artistas em questão. Em seguida, devido ao fato de a letra não estar disponível na internet, fizemos uma escuta atenta seguida do processo de escrita da canção: enquanto os alunos recitavam os versos, eles eram passados para a lousa, sendo respeitada cada estrofe.

"Liberdade dos Funkeiros", dos MCs Márcio e Goró, apresenta explicitamente a identificação do eu-lírico com a negritude. Ao cantarem "Eu sou negro, mas também tenho direito / Eu não tenho culpa de ter nascido assim / Aonde passo sou chamado de suspeito / São essas coisas tolas que eles pensam de mim" (LIBERDADE dos funkeiros, MCs Márcio \& Goró, 1995), os MCs demonstram também os prejuízos que a população negra brasileira sofre cotidianamente por conta do racismo, abrindo caminho para este debate em sala de aula. Uma grave consequência do racismo é a injusta distribuição de direitos sociais, onde um grupo (brancos) tem mais direitos que outros (negros e outros não-brancos). Essa forma de distribuição de direitos em que um grupo os detém frente a outro, transforma o que seriam direitos em privilégios, construídos socialmente por um ideal de poder.

A cada estrofe, analisamos os versos, interpretamos as metáforas contidas 
na canção, refletimos sobre quais mensagens os cantores quiseram passar e avaliamos, juntos, como aquela música estava associada ao contexto dos anos 1990 no Brasil. Ao longo da canção "Liberdade dos Funkeiros", são citadas diversas carências que a população mais pobre é obrigada a encarar: ausência de ensino e saúde de qualidade, presença da fome e necessidade de alimentar-se de restos, insuficiência de salário:

Porque o mundo em que eu vivo está difícil / É sofrimento, sacrifício e muita dor / Crianças morrem comendo coisas do lixo / E quem olha pra ela não reconhece o valor / Saúde, escola, ensino, pode crer / Mas nada adianta eles só pensam em comer / [...] / Pedindo salário digno para os filhos viver. (LIBERDADE dos funkeiros, MCs Márcio \& Goró, 1995)

Assim, os estudantes foram convidados a refletir sobre a canção escutada: cada dupla deveria escolher uma estrofe e apontar ao menos um direito político, civil ou social negado à população brasileira. Dentre as estrofes escolhidas, podemos destacar as seguintes: “A nossa juventude hoje chora / Porque o funk está preso na gaiola / Se a nossa justiça for fiel / Dê liberdade pra ele voar pro céu": ausência de liberdade de expressão; "Eu sou negro, mas também tenho direito / Eu não tenho culpa de ter nascido assim / Aonde passa eu sou chamado de suspeito / São essas coisas tolas que eles pensam de mim": racismo e desrespeito ao princípio da isonomia; "Saúde, escola, ensino, pode crer / Mas nada adianta eles só pensam em comer / E a nossa situação fica cada vez mais precária / E no governo só canalha que não sabe o que fazer": ausência de alimentação e saúde de qualidade, corrupção na política; "Me desculpe se essa letra é muito forte / Eu não abuso da sorte pro que venha acontecer / Eu só quero a liberdade de expressão / Ficar no meu cantinho quieto e ver os meus filhos crescer": ausência de liberdade de expressão; "Eles jogam armadilha em suas mãos / Tu inocentes não tem pra onde correr / Tá agarrado no ódio do pecador / E sem certeza eles batem em você": violência policial e desrespeito à integridade física da pessoa humana. 
Figura 7 - Márcio \& Goró, dupla de MCs que lançou a Liberdade dos Funkeiros, música recheada de crítica social.

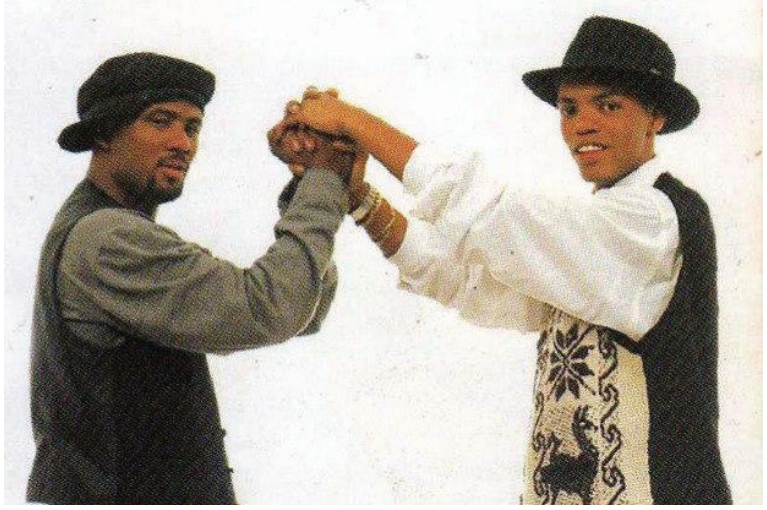

Fonte: ons://odia.ig.com.br/diversao/celebridades/ 2013-0625/marcio-g-se-tornou-queridinho-dos-famosos-e-hoje-seucache-chega-a-r-15-mil.html. Acesso em: 24 abr. 2020.

Esta atividade foi utilizada como um instrumento avaliativo da unidade e os resultados foram satisfatórios.

\section{CONCLUSÃO}

A análise proposta neste artigo sobre o ensino de História e Sociologia a partir do uso de fontes musicais do movimento funk teve grande relevância para a compreensão e inserção de alunos do ciclo básico no contexto cultural, social, histórico e sociológico do funk carioca. Pensar as formas de atravessamento que as aulas poderiam causar na formação dos educandos foi uma maneira não só de descolonizar (OLIVEIRA e CANDAU, 2010) o pensamento a respeito do uso de fontes históricas de favelas e periferias na sala de aula, atravessando o currículo tradicional, mas uma constante busca por uma educação como prática da liberdade, de acordo com o que preconizou Bell Hooks:

Ensinar é um ato teatral e é esse aspecto do nosso trabalho que proporciona espaço para as mudanças, a invenção e as alterações espontâneas que podem atuar como catalisadoras para evidenciar os aspectos únicos de cada turma. [...] Os professores não são atores no sentido tradicional do termo, pois nosso trabalho 
não é um espetáculo. Por outro lado, esse trabalho deve ser um catalisador que conclama todos os presentes a se engajar cada vez mais, a se tornar partes ativas da aprendizagem. (HOOKS, 2013, p. 42)

Além do mais, entende-se que, ao pesquisar a música como fonte histórica para sala de aula, é fundamental compreender as relações e os gostos musicais que atravessam os educandos. Ouvi-los, compreender suas vivências e seus processos formativos também faz parte do processo de ensino-aprendizagem. Por outro lado, pensar a música funk como fonte histórica é um processo que precisa ser analisado, pesquisado e incansavelmente debatido, já que ainda são reduzidas as referências sobre o assunto no ensino básico da educação. É importante também notar que todo o processo de criminalização que o funk recebe está diretamente relacionado à criminalização da juventude negra, pobre e favelada que vivencia, cria e goza dessa arte musical.

Em outras palavras, é fundamental compreender a música em sala de aula como um elemento de pesquisa e de sociabilidade; planejar e contextualizar a música junto ao conteúdo a ser ministrado é um dos aspectos que defendemos, pois é necessário entender toda a estruturação da ideia a partir de um processo de análise das fontes históricas dos documentos. Como aponta Le Goff, os documentos são escolhas feitas pelo historiador (2003) e é nosso dever trabalhar estes e outros processos com os educandos, abrindo nossas práticas pedagógicas à grande dimensão de fontes que podemos utilizar na sala de aula.

\section{REFERENNCIAS}

ALMEIDA, Maria Regina Celestino de. Os índios na história do Brasil. Rio de Janeiro: Editora FGV, 2010.

BOSI, Ecléa. A pesquisa em memória social. Psicologia USP, v. 4, n. 1-2, p. 277-284, 1979.

BRAGANÇA, Juliana da Silva. Preso na Gaiola: A criminalização do funk carioca nas páginas do Jornal do Brasil (1990-1999). Curitiba: Appris, 2020.

BRAICK, Patricia Ramos; MOTA, Myriam Becho. História: das cavernas ao terceiro milênio. 4 ed. São Paulo: Moderna, 2016.

BRASIL. Ministério de Educação e Cultura. LDB Lei no 9394/96, de 20 de dezembro 
de 1996. Estabelece as diretrizes e bases da Educação Nacional. Brasília: MEC, 1996.

BRASIL. Lei 10.639/2003, de 9 de janeiro de 2003. Altera a Lei no 9. 394, de 20 de dezembro de 1996. Diário Oficial da União, Poder Executivo, Brasília.

BRASIL. Lei 11.645, de 10 de marco de 2008.

CETTOLIN, Franciele. Musicando a História e Historiando a Música em Escolas de Caxias do Sul (2008-2014). AEDOS, vol. 7, no 16, julho de 2015, p. 164-83.

ESSINGER, Silvio. Batidão: uma história do funk. Editora Record, 2005.

DE MENEZES, Marcos Antônio. Fraturas no tempo de Eric Hobsbawm. Art cultura, v. 16, n. 29, 2014.

FREIRE, Paulo. Pedagogia da autonomia: saberes necessários à prática educativa. 15. Ed. São Paulo: Paz e Terra, 2000.

GILROY, Paul. O Atlântico Negro como contracultura da modernidade. Rio de Janeiro: Editora, v. 34, 1993.

HERSCHMANN, Micael. O funk e o hip-hop invadem a cena. 2. ed. Rio de Janeiro: Ed. UFRJ, 2005.

HOBSBAWN, Eric J. História social do jazz. Tradução: Anela Noronha. Rio de Janeiro: Paz e Terra, 1990.

HOOKS, Bell. Ensinando a transgredir. A educação como prática da liberdade. 1. ed. São Paulo, 2013.

LE GOFF, Jacques. Documento/monumento. In: LE GOFF, Jacques. In: História e Memória. Campinas: Editora da UNICAMP, p. 525-541, 2003.

LOPES, Adriana Carvalho. Funk-se quem quiser: no batidão negro da cidade carioca. FAPERJ, 2011.

LOPES, Adriana Carvalho et al. A Construção da identidade juvenil no funk carioca. Anais do SETA, v. 1, 2007.

NAPOLITANO, Marcos. História e Música. Belo Horizonte: Autêntica, 2002.

NAPOLITANO, Marcos. História e Música Popular: um mapa de leituras e questões. Revista de História, v. 57, p. 153-171, 2007.

OLIVEIRA, Luiz Fernandes; CANDAU, Vera Maria Ferrão. Pedagogia decolonial e educação antirracista e intercultural no Brasil. Educação em revista [online]. 2010, vol. 26, n. 1, p.15-40.

RATTS, Alex. Eu sou atlântica. Sobre a trajetória de vida de Beatriz Nascimento. São Paulo: Imprensa Oficial do Estado de São Paulo/Instituto Kuanza, 2007.

SÁ, Simone Pereira de. Funk carioca: música eletrônica popular brasileira?! Revista E-COMPÓS, v. 10, a. 2007. 
SOARES, Olavo Pereira; HERMETO, Miriam. Apresentação do Dossiê Música e Ensino de História. Revista História Hoje, v. 6, n. 11, p. 03-06, 2017.

SOARES, Olavo Pereira; HERMETO, Miriam. Entrevista - Marcos Napolitano História e música popular: entre a historiografia contemporânea e as práticas de ensino na Educação Básica. Revista História Hoje, v. 6, n. 11, p. 142-46, 2017.

SOUZA, Carlos Eduardo Dias; SILVA Gladys meire Guimarães. Gênero e reconhecimento no funk carioca: perspectivas para o ensino na educação básica. Revista História Hoje, v. 6, n 11, p. 191-215, 2017.

SPOTTI, Carmem Véra Nunes, et al. "O lugar onde vivo": das narrativas orais indígenas à prática de leitura e de escrita. Nau Literária, vol. 9, n² 2, dezembro de 2013.

VÁRIOS Autores. Sociologia em movimento. 2. ed. São Paulo: Editora Moderna, 2016.

VIANNA, Hermano. O mundo funk carioca. 2. ed. Rio de Janeiro: Jorge Zahar, 1997.

\section{ENTREVISTA}

ARAGOSO, Antônio. Tojão. Entrevista III. [set. 2017]. Entrevistador: Ingra Daniela dos Santos Maciel. Rio de Janeiro, entrevista realizada no Mc Donald's, Penha, 2017. 3 arquivos .mp3 (24 min.).

\section{CANÇÕES}

A FIRMA é forte. Intérpretes: MC Tikão e MC Frank. Informações técnicas desconhecidas. Disponível em: https://www.youtube.com/watch?v=xUlbs0SEb7Y. Acesso em: 24 jul. 2020.

DELAÇÃO Premiada. Intérprete: MC Carol. Compositor: Carolina de Oliveira Lourenço e Leonardo Manfrinato Justi. In: MC CAROL Bandida. VEVO. Niterói: Niterói Records, 2015. Disponível em: https://www.youtube.com/ watch?v=ZfZLPXLGwUs. Acesso em 24 jul. 2020.

LIBERDADE dos funkeiros. Intérpretes: MCs Márcio \& Goró. Compositor: Desconhecido. In: Back to Black, 1995. LP, Lado A.

MONTAGEM Ardendo Assopra. Intérprete: Tati Quebra-Barraco. Compositores: Eduardo Silva, Maicon Evaristo Correa de Souza e Marcos Paulo Ferreira Gomes. In: Boladona, Rio de Janeiro: Link Records, 2000. CD.

NÃO Foi Cabral. Intérprete: MC Carol. Compositor: Carolina de Oliveira Lourenço. In: MC CAROL Bandida. VEVO. Niterói: Niterói Records, 2015. Disponível em: https://www.youtube.com/watch?v=Hfkkeo-Vmc8. Acesso em: 24 jul. 2020.

RAP do Silva. Intérprete: MC Bob Rum. Compositor: Moyses Osmar da Silva. In: RAP Brasil Vol. II. São Paulo: Som Livre, 1995, CD.

SOU Feia, Mas Tô Na Moda. Intérprete: Tati Quebra-Barraco. Compositores: Bruno 
Baranda Cardoso, Ricardo Pinto Gama e Tatiana dos Santos Lourenço. In: Boladona, Rio de Janeiro: Link Records, 2000. CD.

\section{NOTAS}

${ }^{1}$ Torna obrigatória a temática do Ensino da História e da Cultura Afro-Brasileira e Indígena em todos os níveis de ensino.

${ }^{2}$ Para compreender melhor a história do funk e as interações que se deram entre Brasil e Estados Unidos, sugerimos a leitura da obra de Hermano Vianna, O Mundo Funk Carioca.

${ }^{3}$ As melôs eram músicas produzidas com letras em português sobre a base da batida do miami bass e da prática do sampler "de pegar-recortar-copiar-misturar", demonstrando assim o princípio híbrido do funk (SÁ, 2007, p. 6).

${ }^{4}$ ARAGOSO, Antônio. Tojão. Entrevista III. [set. 2017]. Entrevistador: Ingra Daniela dos Santos Maciel. Rio de Janeiro, entrevista realizada no Mc Donald's, Penha, 2017. 3 arquivos .mp3 (24 min.).

${ }^{5}$ Favela chamada de Vila Kenedy, localizada na Zona Oeste da cidade do Rio de Janeiro, território dominado pelo Comando Vermelho.

${ }^{6}$ Também conhecida como AR-baby, está entre as melhores e mais populares armas do mundo. Disponível em: https://pt.wikipedia.org/wiki/AR-15. Acesso em: 24 jul. 2020.

${ }^{7}$ A firma é forte. Intérpretes: MC Tikão e MC Frank. Informações técnicas desconhecidas. Disponível em: https://www.youtube.com/watch?v=xUlbs0SEb7Y. Acesso em: 24 jul. 2020.

${ }^{8}$ Enquanto este artigo era produzido, era realizado o Rock in Rio, um festival de música. Pela primeira vez, desde sua estreia no Brasil em 1985, teve um palco idealizado como Espaço Favela. Tati Quebra Barraco, uma das cantoras mais famosas na cena funk putaria, teve espaço no palco em questão, o que mostra o reconhecimento a cantora no mundo funk carioca e além dele.

${ }^{9}$ MONTAGEM Ardendo Assopra. Intérprete: Tati Quebra-Barraco. Compositores: Eduardo Silva, Maicon Evaristo Correa de Souza e Marcos Paulo Ferreira Gomes. In: Boladona, Rio de Janeiro: Link Records, 2000. CD.

${ }^{10}$ SOU Feia Mas Tô Na Moda. Intérprete: Tati Quebra-Barraco. Compositores: Bruno Baranda Cardoso, Ricardo Pinto Gama e Tatiana dos Santos Lourenço. In: Boladona, Rio de Janeiro: Link Records, 2000. CD.

${ }^{11}$ DJ Rennan da Penha "está muito feliz com a indicação" ao Grammy, diz advogado. $O$ Globo. Rio de Janeiro, 25 set. 2019. Disponível em: https://oglobo.globo.com/cultura/dj-rennan-da-penha-esta-muito-feliz-com-indicacao-ao-grammy-diz-advogado-23974371. Acesso em: 24 jul. 2020

${ }^{12}$ Disponivel em: https://g1.globo.com/rj/rio-de-janeiro/noticia/2019/03/22/justica-deter- 
mina-prisao-de-dj-rennan-da-penha-e-mais-10-envolvidos-no-baile-da-gaiola.ghtml. Acesso em: 24 jul. 2020.

${ }^{13}$ A festa Batekoo é um evento que acontece em algumas regiões do Brasil, entre elas os estados do Rio de Janeiro, São Paulo e Bahia. O evento é considerado pelos participantes e idealizadores um espaço de empoderamento para os grupos sociais minoritários. A festa visa abraçar grupos LGBTQIA+, a população negra e mulheres.

14 "A Base Nacional Comum Curricular é um documento normativo que define o conjunto de aprendizagens essenciais que todos os alunos devem desenvolver ao longo das etapas e modalidades da Educação Básica”. Disponível em: http://basenacionalcomum.mec.gov. br/a-base. Acesso em: 04 abr. 2020.

${ }^{15}$ A BNCC está estruturada a partir de competências e habilidades. As competências gerais são aquelas que "os alunos devem desenvolver ao longo de todas as etapas da Educação Básica”, tendo cada área do conhecimento suas competências específicas e as habilidades, "relativas a diversos objetos do conhecimento [...] que os alunos devem desenvolver em cada etapa da Educação Básica”. Disponível em: http://basenacionalcomum.mec.gov.br/a-base. Acesso em: 24 jul. 2020.

${ }^{16}$ As competências e habilidades de número cinco da BNCC tratam de orientações para formação e construção de uma educação autônoma e crítica para alunos, tendo como base a) a formação baseada em princípio ético; b) a valorização de princípios ausentes de preconceitos; c) a valorização de princípios pautados nos direitos humanos; d) a construção crítica para identificação das variáveis formas de violência contra diversos grupos sociais e e) identificação das abordagens e envolvimentos políticos, baseados na formação cultural, histórica, cientifica e social.

${ }^{17}$ Disponível em http://g1.globo.com/rio-de-janeiro/musica/noticia/2015/07/professores-analisam-funk-de-mc-carol-que-contesta-historia-do-brasil.html. Acesso em: 24 jul. 2020.

${ }^{18}$ Sugerimos como complemento de leitura o seguinte livro: ALMEIDA, Maria Regina Celestino de. Os índios na história do Brasil. Rio de Janeiro, Editora FGV, 2010.

${ }^{19}$ RATTS, Alex. Eu sou atlântica. Sobre a trajetória de vida de Beatriz Nascimento. São Paulo: Imprensa Oficial do Estado de São Paulo: Instituto Kuanza, 2007.

${ }^{20}$ É regra geral do Colégio Estadual do Campo de Ibititá a que a última avaliação seja uma prova composta por oito questões objetivas.

Artigo recebido em 9 de abril de 2020. Aprovado em 26 de julho de 2020. 